\title{
Gene tests lift lid on drug-resistance puzzle
}

\section{Jonathan Knight, Orlando}

Is the use of antibiotics in farm animals causing the spread of antibiotic-resistance genes to human pathogens? The jury is still out, say experts who gathered last week at the annual meeting of the American Society for Microbiology in Orlando, Florida. But this long-standing controversy could soon be resolved, thanks to the development of molecular tools to help recognize resistance genes that originated on the farm.

Infections that resist treatment with antibiotics are a growing problem. Most researchers agree that over-prescription of antibiotics by doctors is the main cause.

But antibiotics are also routinely added to the feed of farm animals as minor infections can stunt their growth. This is promoting the emergence of antibiotic resistance among bacteria that inhabit or infect livestock. And such bacteria have been shown to cause some cases of human food poisoning.

More worrying, however, is the possibility that farmyard antibiotic-resistance genes could be transferred to the bacteria that inhabit our bodies, creating an insidious reservoir of drug resistance. But it has proved difficult to demonstrate whether or not such gene transfer is occurring.

"It's hard to get agreement on the extent of the problem," says Walter Hill, an official with the US Department of Agriculture's Food Safety and Inspection Service.

Among those investigating the connection between farm antibiotics and human health is David Wagner, an animal scientist at the Food and Drug Administration's Center for Veterinary Medicine in Laurel, Maryland. He collected microorganisms from beef and poultry at local supermarkets, and found that two-thirds of one species of gut bacterium, Enterococcus faecium, sampled from chicken, were resistant to Synercid. This antibiotic has only been on the market for two years, and is used as a last resort to treat infections that resist the more commonly used vancomycin.

Although Synercid is not used in agriculture, its close cousin virginiamycin has been given to cattle, pigs and poultry for more than 20 years in the United States and Europe. Genes for virginiamycin resistance also confer resistance to Synercid, and the possibility that they can be transferred to human pathogens is a serious concern. "This is not good news," says Wagner of his findings.

Synercid treatment currently fails in only a tiny proportion of cases. But Stuart Levy of Tufts University in Boston, whose work on antibiotic resistance helped to open the field, advises caution. If resistance genes do transfer from livestock bacteria to those infecting humans, they could spread rapidly if Synercid becomes more widely used.

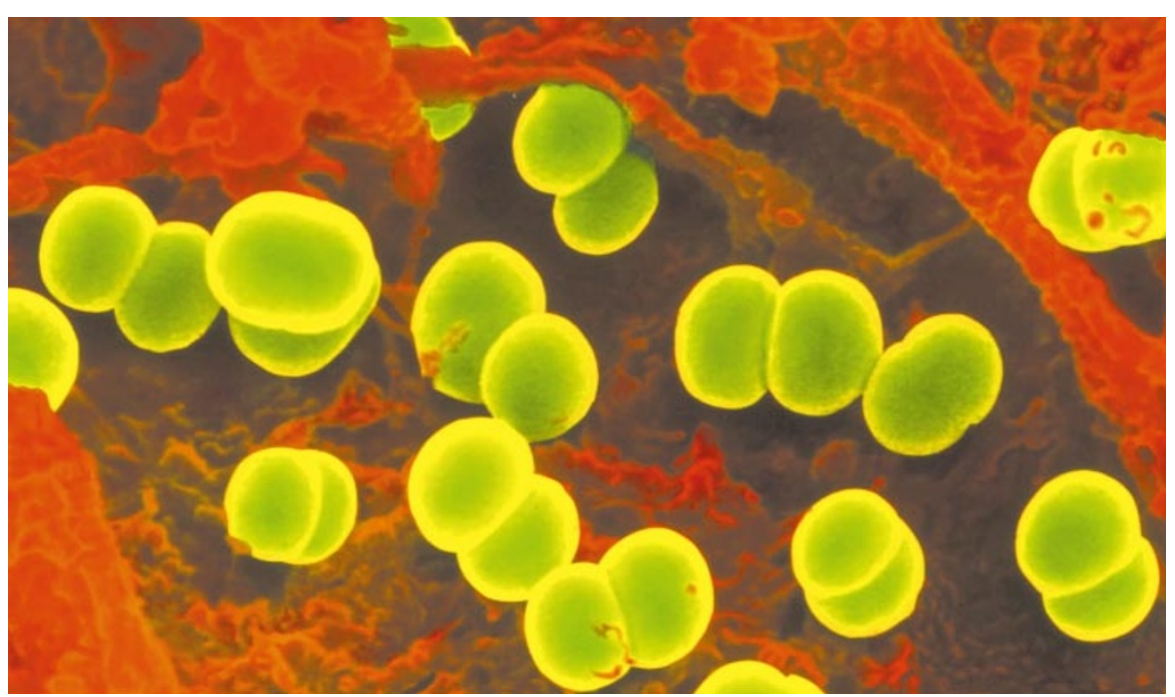

Meaty issue: are farming practices to blame for resistance in human pathogens such as Enterococcus?

Other researchers are now using molecular techniques that can rapidly recognize specific mutations involved in antibiotic resistance. Roustam Aminov of the University of Illinois at Urbana-Champaign has developed tests, based on the polymerase chain reaction, that can identify eight different classes of gene that confer resistance to tetracycline. Bacteria from cows and pigs carry different characteristic combinations of resistance genes, and Aminov has used his tests to track the transfer of tetracycline-resistance genes from pig farms in Illinois to soil bacteria.

Mark Maiden, a geneticist at the Forsyth Institute in Boston, Massachusetts, has used similar tests and found matching tetracyclineresistance genes in human mouth bacteria and in bacteria from animal intestines. "You've got identical sequences turning up in quite different species," he says. "That's highly symptomatic of horizontal gene transfer."

Although oral bacteria cause nothing worse than dental cavities, Maiden says they could serve as a reservoir of tetracyclineresistance genes that might transfer to opportunistic bacteria that cause pneumonia or postoperative infections, making these more difficult to treat.

Maiden says he cannot prove that the genes did transfer from the animals' bacteria to the human oral bacteria - in theory, it could have been the other way around. But microbiologists are optimistic that the application of such molecular methods by more researchers will soon reveal the extent to which the transfer of farmyard resistance genes to human pathogens is occurring. "We've needed this for many years," says Levy.

\section{Bioinformatics to be nurtured online}

\section{Declan Butler}

Attempts to address the worldwide shortage of bioinformaticists have received a boost with the announcement that six academic centres will provide free online accredited bioinformatics courses.

The pre-release website for the Global Genomics and Bioinformatics Unified Learning Environment (GLOBULE) is already available, and features a series of video lectures from some of the biggest names in bioinformatics. They include Russ Altman of Stanford University in California and Winston Hide, director of the South African National Bioinformatics Institute at the University of the Western Cape.

Pitched at third-year undergraduate level and above, the site will allow students to interact with teachers and other students around the world by e-mail and through chat rooms, says Tony Weiss, director of the Molecular Biotechnology Program at the University of Sydney in Australia. The finished version will offer a range of modules that will be credited by members of the consortium.

The programme could make a dramatic difference to the growth of genomics in developing countries, says Hide.

The founding members of the 'S-Star' consortium are Stanford University, Sweden's Uppsala University and Karolinska Institute, the National University of Singapore, the University of Sydney and the University of the Western Cape. http://www.s-star.org 